\title{
The Effect of Buzz Group Modification Method on Exclusive Breastfeeding Against Self Efficacy in Pregnant Women: A Quasi Experiment
}

\author{
Febyana Dwi Cahyantia ${ }^{1}$, Lailatun Nimah ${ }^{1}$, Retnayu Pradaniea ${ }^{1}$ \\ ${ }^{1}$ Faculty of Nursing, Universitas Airlangga, Surabaya, Indonesia, Universitas Airlangga Kampus C, Jl. Mulyorejo, \\ Surabaya, Kota SBY, Jawa Timur
}

\begin{abstract}
Background: Exclusive breastfeeding for six months is an effort to increase the breastfeeding benefits and reduce infant mortality rate. Self efficacy is one of the factors that can influence the level of confidence exclusive in breastfeeding.

Aim: This study aimed to identify the level of self efficacy before and after given modified buzz group method and to the influence of modified buzz group method about exclusive breastfeeding against self efficacy in pregnant mother

Method: This study was designed using quasi-experimental design. The study was conducted in the working area of the health center. The total population used in this study was 42 pregnant women. A total sample of 38 respondents was taken according to purposive sampling. BSES-SF (Breastfeeding Self Efficacy Scale Short Form) questionnaire was administered at pre-test and post-test. Data analysis was performed using the Wilcoxon Signed Rank test and the Mann Whitney test.

Results: The results showed that the Wilcoxon Signed Rank statistical test obtained p value of 0,000 in the treatment group and $p$ value of 0.355 in the control group. The Mann Whitney statistical test obtained a significant value of $p=0,000$ at the post-test. The modification of the buzz group method took effect to increased self efficacy about exclusive breastfeeding for pregnant mother because this method was organized by four sources of self efficacy that was direct experience, indirect experience, verbal persuasion, and emotional condition.
\end{abstract}

Conclusion: With the modification of the buzz group method and self efficacy for pregnant mother can increase of value for breastfeeding exclusive coverage.

Keywords: Buzz Group Modification, Buzz Group Method, Self-Efficacy, Breastfeeding Self-Efficacy

\section{Introduction}

Breast milk can help infants to start life well, the content in breast milk can meet all food needs such as nutrition and immunology. Giving exclusive breastfeeding for 6 months and continued with breastfeeding for 2 years can enhance spiritual (SQ) and emotional (EQ) abilities ${ }^{1}$. Problems that cause mothers not to exclusively breastfeed are lack of knowledge about the breastfeeding benefits, proper breastfeeding, lack of lactation counseling services and support from health workers, socio-cultural perceptions against breastfeeding, and lack of motivation to breastfeed. Psychological factors are one of the factors that influence one's level of confidence. Self efficacy is a person's belief to do a specific task or behavior ${ }^{2}$.

Self-efficacy or self-confidence is one important factor in the success of giving exclusive breastfeeding. There was study examined that the lower the self-efficacy of a person, the lower the success rate. Until now there are still mothers who are worried that the production of breast milk is a little, thus, the reality that occurs mothers really experience disruptions in the production 
of breastfeeding ${ }^{3,4}$. Many ways have been done by the government to socialize exclusive breastfeeding, namely the formation of government regulation number 33 of 2012 concerning exclusive breastfeeding and various kinds of study on exclusive breastfeeding have been done, but until now Indonesia has not been able to achieve the target that was set by the government in 2010, namely coverage exclusive breastfeeding for infants aged 0-6 months is around $80 \%$. This can be seen from the results of a health service survey in 2015, the coverage of exclusive breastfeeding in Indonesia from 0-6 months of infants was $55.7 \%$ with an increase of $3.4 \%$ from the previous year which was $52.3 \%{ }^{5,6}$. Selfefficacy for breastfeeding is an action that cannot be separated by the mother's belief in giving breastfeeding to her infant. There are various factors that make up self-efficacy such as direct experience, the experience of others, verbal persuasion, physical, and emotional state ${ }^{7}$.

Pucang Sewu Public Health Center is one of the public health centers in the Surabaya city area of Indonesia that has low breastfeeding coverage rates. Pucang Sewu public health center has a class of pregnant women which is held once a month. The number of pregnant women in attendance is not proportional to the number of pregnant women recorded in the public health center. This happens because of many factors, one of which is the absence of a companion during a class of pregnant women, the lack of motivation of mothers to come, and less varied learning methods. The use of the buzz group method is a considered as appropriate way to eliminate these factors because this method has never been used during a class of pregnant women and considered as an update way of teaching material. The results of the study mentioned the role of the buzz group method in an effort to improve learning outcomes in fiqih material can be stated sufficient or moderate. Other study results revealed that there was an influence of the buzz group discussion method with the uno card game on student collaboration and the ability to solve student problems.

Based on this background the writers intended to provide a buzz group method modification in the class of pregnant women aimed at increasing the self-efficacy of pregnant women related to exclusive breastfeeding, hence it is expected that after giving birth mothers will exclusively give breast milk.

\section{Method}

This study used a quasi-experimental design. The independent variable in this study was the buzz group on the dependent variable, namely the self-efficacy of pregnant women in exclusive breastfeeding. Buzz group was a large group which was divided into several small groups, consisting of 4-5 people. An impromptu group consisting of no more than five people will make all group members actively involved in the discussion. The place was arranged so that participants can have their faces covered and exchange ideas easily. Buzz groups also assigned each large group member and group leader. The next stage, small groups gathered and discussed, then returned to the large group, which then conveyed ideas that arise in the group. At the end of the session, the facilitator asked each group to actively participate in delivering the results of the discussion. This method can build an atmosphere of mutual respect for differences of opinion and also increase the participation of participants who still did not talk much in broader discussions and can develop a common opinion or agreement to find a best formulation of an issue.

The population in this study was pregnant women in the working area of the Pucang Sewu Public Health Center. The population in this study was 42 pregnant women. Based on the formula, the minimum sample size used was 38 respondents. The 38 sample results were divided into 2 groups: 19 for the control group and 19 for the experimental group, with inclusion criteria: (1) Mothers can read, write and hear (2) Late trimester pregnant women recorded in the Pucang Sewu Puskesmas. Furthermore, the exclusion criteria are: (1) Pregnant women with chronic or infectious diseases (HIV, TB, cancer, hepatitis). (2) Pregnant women who did not have permanent residences.

The sampling used by writers was nonprobability sampling that was purposive sampling. Data collection instruments used in this study were in the form of informed consent, questionnaire sheets, stationery, booklets and turning sheets about exclusive breastfeeding, and respondents. The instrument in this study used the Breastfeeding Self Efficacy Scale Short Form (BSESSF) containing 14 questions about confidence and confidence in breastfeeding. Each question has a 5-point Likert scale and summed. This instrument was compiled by Dennis in 2003 and has been declared valid and reliable ${ }^{8}$. 
The data collected was analyzed the differences in self-efficacy changes before and after the intervention was given, such as buzz group method modification with the Wilcoxon Signed Rank Test. The Mann Whitney test was carried out to analyze the differences between the two groups, the treatment group and the control group, with significance level $p \leq 0.05$ meaning that if the statistical test showed the value of $\mathrm{p} \leq$ then $\mathrm{H} 1$ is accepted. This study has been through a review and has been declared "Eligible Ethics" with a Certificate of Ethical Feasibility from the Faculty of Nursing, Universitas Airlangga, Surabaya Indonesia.

\section{Results}

\section{Characteristics of Respondents}

The following is the respondent's characteristic data.

Table 1: Characteristics of Respondents

\begin{tabular}{|c|c|c|c|c|}
\hline \multicolumn{3}{|l|}{ Control Group } & \multicolumn{2}{|c|}{ Treatment Group } \\
\hline & $\mathbf{F}$ & $\%$ & f & $\%$ \\
\hline $\begin{array}{l}\text { Age } \\
20-30 \\
31-40 \\
>40 \text { years old }\end{array}$ & $\begin{array}{l}15 \\
4 \\
0\end{array}$ & $\begin{array}{l}78,9 \\
21,1 \\
0\end{array}$ & $\begin{array}{l}9 \\
9 \\
1\end{array}$ & $\begin{array}{l}47,4 \\
47,4 \\
5,3\end{array}$ \\
\hline $\begin{array}{l}\text { Last Education } \\
\text { Elementary School } \\
\text { JHS } \\
\text { SHS } \\
\text { Fresh graduate }\end{array}$ & $\begin{array}{l}2 \\
7 \\
6 \\
4\end{array}$ & $\begin{array}{l}10,5 \\
36,8 \\
31,6 \\
21,1\end{array}$ & $\begin{array}{l}5 \\
5 \\
9 \\
0\end{array}$ & $\begin{array}{l}26,3 \\
26,3 \\
47,4 \\
0\end{array}$ \\
\hline $\begin{array}{l}\text { Pregnant } \\
\text { 1st } \\
\text { 2nd } \\
\text { 3rd } \\
4 \text { th } \\
\text { 5th }\end{array}$ & $\begin{array}{l}8 \\
7 \\
3 \\
1 \\
0\end{array}$ & $\begin{array}{l}42,1 \\
36,8 \\
15,8 \\
5,3 \\
0\end{array}$ & $\begin{array}{l}2 \\
9 \\
5 \\
1 \\
2\end{array}$ & $\begin{array}{l}10,5 \\
47,4 \\
26,3 \\
5,3 \\
10,5\end{array}$ \\
\hline $\begin{array}{l}\text { Work } \\
\text { House maid } \\
\text { Staff } \\
\text { Public servant }\end{array}$ & $\begin{array}{l}14 \\
3 \\
2\end{array}$ & $\begin{array}{l}73,7 \\
15,8 \\
10,5\end{array}$ & $\begin{array}{l}13 \\
6 \\
0\end{array}$ & $\begin{array}{l}68,4 \\
31,6 \\
0\end{array}$ \\
\hline
\end{tabular}

\section{Self Efficacy}

Herewith the result of self-efficacy in the treatment and control group 
Table 2 : Self efficacy before and after given buzz group method modification

\begin{tabular}{|c|c|c|c|c|c|c|c|c|c|}
\hline \multirow{4}{*}{$\begin{array}{l}\text { Self efficacy } \\
\text { High }\end{array}$} & \multicolumn{4}{|c|}{ Control Group } & \multicolumn{5}{|c|}{ Treatment Group } \\
\hline & \multicolumn{2}{|c|}{ Pre-test } & \multicolumn{2}{|c|}{ Post-test } & \multicolumn{3}{|c|}{ Pre-test } & \multicolumn{2}{|c|}{ Post-test } \\
\hline & f & $\%$ & f & $\%$ & $\mathbf{f}$ & & $\%$ & $\mathbf{F}$ & $\%$ \\
\hline & 3 & 15,8 & 5 & & 26,3 & 3 & 15,8 & 18 & 94,7 \\
\hline Medium & 13 & 68,4 & 14 & & 73,7 & 15 & 78,9 & 1 & 5,3 \\
\hline Low & 3 & 15,8 & 0 & & 0 & 1 & 5,3 & 0 & 0 \\
\hline Total & 19 & 100 & 19 & & 100 & 19 & 100 & 19 & 100 \\
\hline
\end{tabular}

The Effect of buzz group method modification of exclusive breastfeeding against self efficacy in pregnant women

Herewith the result of the differences between self-efficacy of exclusive breastfeeding before and after given the intervention such as buzz group method modification

Table 3 : The Effect of buzz group method modification of exclusive breastfeeding against self efficacy in pregnant women

\begin{tabular}{|c|c|c|c|c|c|c|}
\hline \multirow{3}{*}{ No. } & \multicolumn{6}{|c|}{ Self efficacy } \\
\hline & \multicolumn{3}{|c|}{ Control Group } & \multicolumn{3}{|c|}{ Treatment Group } \\
\hline & Pre-Test & Post-Test & Deviation & Pre-Test & Post-Test & Deviation \\
\hline 1. & 51 & 49 & 2 & 46 & 53 & 7 \\
\hline 2. & 50 & 48 & 2 & 43 & 54 & 11 \\
\hline 3. & 49 & 50 & 1 & 44 & 53 & 9 \\
\hline 4. & 47 & 48 & 1 & 40 & 55 & 15 \\
\hline 5. & 39 & 41 & 2 & 51 & 58 & 7 \\
\hline 6. & 38 & 40 & 2 & 44 & 51 & 7 \\
\hline 7. & 38 & 38 & 0 & 51 & 51 & 0 \\
\hline 8. & 39 & 39 & 0 & 45 & 54 & 9 \\
\hline 9. & 44 & 44 & 0 & 39 & 52 & 13 \\
\hline 10 & 35 & 37 & 2 & 43 & 47 & 4 \\
\hline 11. & 36 & 43 & 7 & 44 & 55 & 11 \\
\hline 12. & 46 & 40 & 6 & 45 & 55 & 10 \\
\hline 13. & 46 & 44 & 2 & 39 & 53 & 14 \\
\hline 14. & 47 & 48 & 1 & 38 & 54 & 16 \\
\hline 15. & 39 & 39 & 0 & 48 & 53 & 5 \\
\hline 16. & 40 & 41 & 1 & 36 & 60 & 24 \\
\hline 17. & 41 & 42 & 1 & 44 & 52 & 8 \\
\hline 18. & 35 & 37 & 2 & 46 & 54 & 8 \\
\hline 19. & 40 & 41 & 1 & 40 & 50 & 10 \\
\hline Average Score & 42.11 & 42.58 & 1,74 & 43,47 & 53,37 & 9,89 \\
\hline Wilcoxon & \multicolumn{3}{|l|}{$\mathrm{p}=0,355$} & \multicolumn{3}{|l|}{$\mathrm{p}=0,000$} \\
\hline $\begin{array}{l}\text { Mann Whitney Pre- } \\
\text { Test }\end{array}$ & \multicolumn{6}{|l|}{$\mathrm{p}=0,412$} \\
\hline $\begin{array}{l}\text { Mann Whitney Post- } \\
\text { Test }\end{array}$ & \multicolumn{6}{|l|}{$\mathrm{p}=0,000$} \\
\hline $\begin{array}{l}\text { Mann Whitney } \\
\text { Selisih }\end{array}$ & \multicolumn{6}{|l|}{$\mathrm{p}=0,000$} \\
\hline
\end{tabular}




\section{Discussion}

The results examined that self-efficacy of the control group and the treatment group before getting the intervention got the same score that was moderate. Self-efficacy was a person's belief to do positive things, thus it affected motivation, thought processes, emotional conditions, and social environment that shows a habit. Self-efficacy for mothers was considered as important for breastfeeding activities and can provide an illustration, especially for health workers about mothers' readiness in providing nutrition with breast milk for their babies. The level of self-efficacy of a person in each task varies greatly. This arises due to factors that influence the perception of an individual's abilities such as gender, age, level of education and experience ${ }^{9}$.

Based on the results of the study, respondents with primary education have low to moderate self-efficacy, such as control group respondents number 10 who have low self-efficacy because mothers cannot read fluently and also lack of knowledge about breastfeeding. Control group respondent no. 1 and 2 were respondents with a high education level, namely tertiary institutions with high self-efficacy scores, this was due to the large amount of information that mothers have obtained from various books and internet sources. Individuals who have higher levels have higher self-efficacy, because basically they learnt more and receive more formal education, besides individuals who have higher education levels will get more opportunities to learn in overcoming problems ${ }^{10}$.

The number of children was one thing that influenced the practice of breastfeeding. Most respondents were mothers with more than one child. This will increase the experience of mothers in breastfeeding. The number of children influenced the mother's knowledge because the practice of nursing mothers was closely related to the learning process of the practice of the previous child. The results revealed that self-efficacy after intervention in the treatment and control groups were different. These results were reinforced by the post-test conducted 1 week after the intervention. This referred to a theory that explained that the effective time to carry out a posttest should be within a week after the intervention. The treatment group, which initially had an average level of self-efficacy after being intervened, became a high average, in contrast to the control group which had no significant changes after the intervention ${ }^{4,11}$.

The experience of success or direct experience can increase the confidence and strong desire of the respondent. A sense of success can also increase the persistence and persistence of respondents during the process, so as to reduce failure. Mothers who have direct breastfeeding experience tend to be more confident to continue breastfeeding. There were 6 respondents who gave non-exclusive breastfeeding to their children, and the six respondents had a moderate level of selfefficacy. There were 3 respondents who had successfully provided exclusive breastfeeding and the three people had high self-efficacy. The learning pyramid theory Edgar Dale explains that a person's learning outcomes were obtained by direct experience (concrete). Learning that referred to Edgar Dale's pyramid theory reinforced direct experience, through direct experience practice will provide information and ideas contained in that experience, because it involved the sense of sight, hearing, feeling, smell, and touch ${ }^{8}$.

Someone's self-efficacy can increase especially if she believes she can do the action because she sees that other people have succeeded in doing so. Individuals will have a tendency to increase motivation and confidence to take action if they see that those who have already been able to succeed through the problem. Small groups when implementing the buzz group modification get problems that were discussed in groups, this allowed for mothers who have experience in giving breastfeeding to tell the inexperienced, thus it can bring self-efficacy to inexperienced mothers ${ }^{3,12}$.

Buzz group modification activities can encourage shy individuals to contribute thoughts to participate in discussions and create a pleasant atmosphere so that pregnant women can receive information with happy feelings ${ }^{12,13}$. Respondents from the treatment group got an increase with high self-efficacy values, there was only 1 respondent did not experience it. This was because respondent number 10 was in a hurry to go home soon because her first child was sick. In terms of age, the respondent was 34 years old enough, in terms of the experience of the respondent she also has 2 children and now his third pregnancy, the first child was not exclusively breastfed because of work and the second child was exclusively breastfed, in terms of education.

The control group did not experience a significant increase in self efficacy about exclusive breastfeeding. The increase in self efficacy about exclusive breastfeeding in the control group only slightly increased, it happened because after the pre-test the control group followed the class of pregnant women who also coincided 
with discussing the material of breast milk, namely understanding breastfeeding, understanding exclusive breastfeeding, and how to express milk. The activity was one form of verbal persuasion, where verbal persuasion was one source of self-efficacy. Another factor that made the increase in the control group was that the writers gave a handbook on pregnancy to respondents as souvenirs during the pre-test and every Monday and Thursday there was an examination of pregnant women, meaning that there were pregnant women who received additional information when attending examination. Therefore, after a post-test one week later there was still a shadow about breast milk making a slight increase in the control group.

\section{Conclusion}

Submitting material with a modification of the buzz group method was a powerful way to increase self-efficacy about exclusive breastfeeding to pregnant women, because at home pregnant women can re-study the material discussed.

Source of Funding: This research was fund by author

Conflict of Interest: There is no conflict of interest

\section{References}

1. Organization WH. Global nutrition targets 2025: Breastfeeding policy brief. World Health Organization; 2014.

2. Gökçeo E, Küçüko S. Original Article The relationship between insufficient milk perception and breastfeeding self-efficacy among Turkish mothers. 2016;24(March 2015):53-61.

3. Li T, Guo N, Jiang H, Eldadah M. Breastfeeding Self-Efficacy Among Parturient Women in Shanghai : A Cross-Sectional Study. 2018;(2699).
4. Blyth R, Hons M, Creedy DK, Dennis C, Moyle W, Rn JP, et al. Effect of Maternal Confidence on Breastfeeding Duration: An Application of Breastfeeding Self-Efficacy Theory. 2002;(December):278-84.

5. Dasar RK. RISKESDAS 2013. Jakarta Kementeri Kesehat RI. 2013;

6. Kementerian Kesehatan RI. Info Datin Situasi dan Analisis ASI. Jakarta Kementrian Kesehat RI. 2014;

7. Semasaka JPS, Krantz G, Nzayirambaho M, Munyanshongore C, Edvardsson K, Mogren I. Self-reported pregnancy-related health problems and self-rated health status in Rwandan women postpartum: a population-based cross-sectional study. BMC Pregnancy Childbirth [Internet]. 2016; Available from: http://dx.doi.org/10.1186/s12884016-1138-y

8. Dennis C. The breastfeeding self-efficacy scale: Psychometric assessment of the short form. J Obstet Gynecol Neonatal Nurs. 2003;32(6):734-44.

9. I SAD, I TQS, I DOV, Fayma A, Chaves L, Carolina A, et al. Breastfeeding self-effi cacy among blind mothers. 2018;71(6):2969-73.

10. Breastfeeding E, Glassman ME, Mckearney K, Saslaw M, Sirota DR. Impact of Breastfeeding Self-Efficacy and Sociocultural. 2014;9(6):301-7.

11. Bastani F, Rahmatnejad L, Jahdi F, Haghani H. Breastfeeding self efficacy and perceived stress in primiparous mothers. Iran J Nurs. 2008;21(54):924.

12. Nichols J, Schutte NS, Brown RF, Dennis C-L, Price I. The impact of a self-efficacy intervention on short-term breast-feeding outcomes. Heal Educ Behav. 2009;36(2):250-8.

13. Brown A, Raynor P, Lee M. Young mothers who choose to breast feed: the importance of being part of a supportive breast-feeding community. Midwifery. 2011;27(1):53-9. 